\title{
MIXED LIGAND COMPLEXES CONTAINING SCHIFF BASES AND THEIR BIOLOGICAL ACTIVITIES: A SHORT REVIEW
}

\author{
M. M. El-ajaily ${ }^{1}$, A. A. Maihub ${ }^{2}$, U. K. Mahanta ${ }^{3}$, G. Badhei ${ }^{4}$, \\ R. K. Mohapatra ${ }^{5, *}$ and P. K. Das ${ }^{6}$ \\ ${ }^{1}$ Chemistry Department, Faculty of Science, University of Benghazi, Benghazi (Libya) \\ ${ }^{2}$ Chemistry Department, Faculty of Science, University of Tripoli, Tripoli (Libya) \\ ${ }^{3}$ Department of Chemistry, B. B. Mahavidyalaya, Harichandanpur, Keonjhar, Odisha (India) \\ ${ }^{4}$ Department of Chemistry, SKDAV Government Polytechnic, Rourkela, Odisha (India) \\ $5^{*}$ Department of Chemistry, Government College of Engineering, Keonjhar, Odisha (India) \\ ${ }^{6}$ P. G. Department of Chemistry, G. M. University, Sambalpur, Odisha (India) \\ *E-mail: ranjank_mohapatra@yahoo.com
}

\begin{abstract}
Schiff bases are organic compounds, considered to be a subclass of imines, which may be secondary aldimines or ketimines depending on the nature of the parent carbonyl compounds, which are synthesized by nucleophilic addition of aliphatic or aromatic amines with carbonyl compounds forming intermediate hemiaminals followed by elimination of water, the reaction often being catalyzed in acid medium. They have the general formula R-CH=NR' where $\mathrm{R}^{\prime} \neq \mathrm{H}$. The presence of the azomethene function in the Schiff base compounds renders them as potential candidates for forming a wide range of complex compounds with both transition and nontransition metal ions. This class of compound has been found to exhibit a broad range of biological activities including antibacterial and antifungal properties. This article presents a short overview of the synthetic design and biological activities of a host of mixed ligand complexes containing Schiff base moieties.
\end{abstract}

Keywords: Schiff base, Mixed ligand complexes, Synthesis, Biological activities

(C) RASĀYAN. All rights reserved

\section{INTRODUCTION}

The Schiff bases ${ }^{1}$ were first synthesized by Hugo Schiffs (German chemist) in 1864. These compounds were classified as a class of organic compounds and these compounds contain a group known as imine (azomethine) of the formula $(\mathrm{R}-\mathrm{C}=\mathrm{N})$, where, $\mathrm{R}$ represents alkyl or aryl group, this group formed from the condensation of primary amines and carbonyl group of the aldehydes or ketones in the presence or absence of acids or bases in organic solvents such alcohols, where, the hydrogen atoms of the primary amines react with oxygen atom of the carbonyl group to form water molecule and the other product named a Schiff base. The Schiff bases are generally bi- or tridentate ligands capable of forming very stable complexes with metal ions. The general chemical structure of the Schiff base compound is shown in Fig-1.

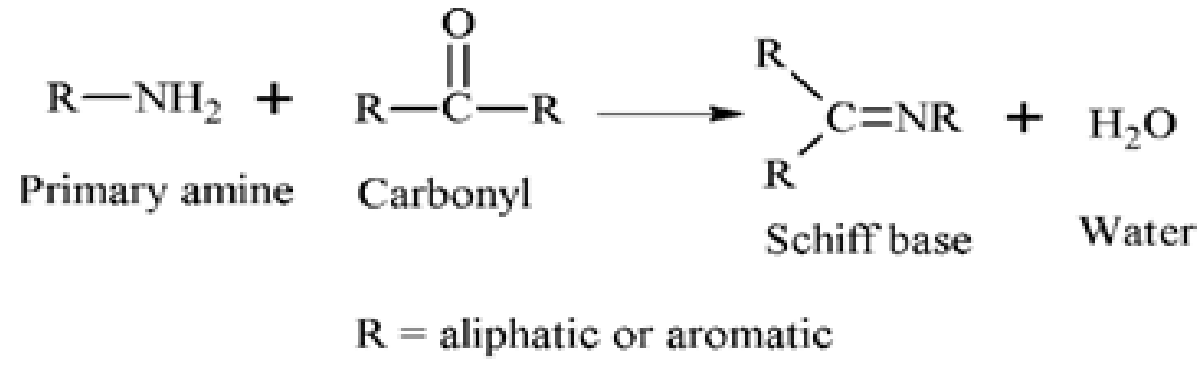

Fig-1: Reaction of amine with carbonyl to produce Schiff base 
RASĀYAN J. Chem.

Vol. 11 | No. 1 |166-174 | January - March | 2018

In this review, we wish to present little information on the role of Schiff base and heterocyclic compounds in coordination chemistry, Also this review is concerned on the biological activity of many mixed ligand complexes against several pathogenic bacterial and fungal species.

\section{Mixed Ligand Complexes}

$\mathrm{Mn}$ (II) and Co(II) mixed ligand complexes ${ }^{2}$ of salicylaldehyde (1) and 6-Formyl-7-hydroxy-5-methoxy2-methylchromone (2) have been prepared and characterized by using elemental analysis, molar conductance measurements and infrared spectroscopy. The molar conductance indicated that the synthesized complexes are non-electrolytic, whereas IR spectra displayed that the chelation takes place through the aldehydic group in position 6 and a hydroxyl group in position 7 of the chromone moiety and the same functional groups of the salicylaldehyde moiety.

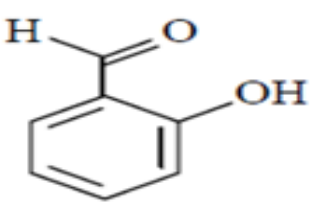

(1)

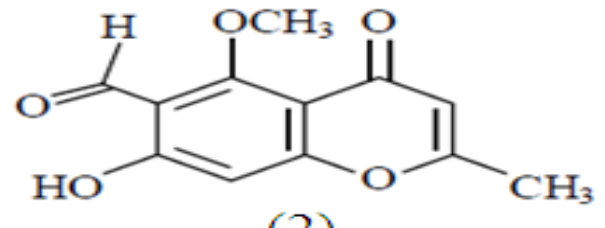

(2)

The modified bio-ligands has increased and played a good role in coordination chemistry ${ }^{3}$. The characterization has been observed for potential biological activities of complexes. The Schiff bases have very important role due to their physiological and pharmaceutical activities and also they are of wellknown structures for antimicrobial and antiviral agents ${ }^{4}$. Many Schiff base complexes were reported and indicate that their biological activities are more active than free Schiff bases. This is due to chelation formation which decreases the polarity of the metal ions ${ }^{5}$.

The Co(II), Cu(II), Ni(II) and Zn(II) complexes with a new bidentate NO type Schiff base ligand obtained from 4-dimethylaminobenzaldehyde and 2-aminophenol (main ligand) and $l$-Alanine (co-ligand) have been synthesized by El-ajaily et $a l^{6}$. Schiff base and its mixed ligand chelates were characterized by various physicochemical tools and showed an octahedral structure.

$\mathrm{Cu}$ (II) mixed ligand complexes with salicylaldehyde and acetylacetone were prepared by Doraswamy et $a l^{7}$. On treatment of the mixed ligand complex with ammonia, methyl or ethylamine, only the salicylaldehyde molecule forms Schiff base, acetylacetone remaining unreacted. The above Schiff base complex may also be prepared by treating the metal amine complex with an equivalent amount of salicylaldehyde and acetylacetone. Amine exchange reactions are also possible. These complexes were investigated by several physiochemical techniques.

Five $\mathrm{Co}(\mathrm{II}), \mathrm{Cu}(\mathrm{II}), \mathrm{Ni}(\mathrm{II}), \mathrm{Zn}(\mathrm{II})$ and $\mathrm{Fe}(\mathrm{III})$ mixed ligand Schiff base complexes with two different Schiff bases, namely\{2-((2-hydroxy-1-phenylethylidene)amino)-3-(4-hydroxyphenyl)propanoic acid derived from 2-hydroxyacetophenone and tyrosine as main ligand and \{4-((2-) (2,4dinitrophenyl)hydrazono)methyl)-N,N-dimethylaniline\} derived from 4-dimethylamino benzaldehyde and 2,4-dinitrophenylhydrazine as a second ligand were prepared by Al-barki et al $^{8}$. The above Schiff bases and their mixed Schiff base complexes were characterized by several physiochemical tools.It has been shown that the metal ions were coordinated through the nitrogen atom of azomethine and the oxygen atom of the hydroxyl group of the ligands. It has also been suggested that there is an octahedral geometry around the metal ions. Four mixed-ligand $\mathrm{Cu}$ (II) and $\mathrm{Ni}$ (II) complexes with a Schiff base derived from the reaction of salicylaldehyde and 4-methyl-3-thiosemicarbazide as main ligand and either benzimidazole or imidazole as co-ligand have been synthesized and characterized ${ }^{9}$.

\section{Biological Activities of Mixed-Ligand Complexes}

The interest in the field of bioinorganic chemistry has increased in the mixed ligand complexes containing Schiff base compounds, since it has been recognized that many of these types of the complexes may serve as models for biologically important species. 
RASĀYAN J. Chem.

Vol. 11 | No. 1 |166-174 | January - March | 2018

Mahmoud et $\mathrm{al}^{10}$ synthesized and examined eight mixed ligand complexes of $\mathrm{Mn}(\mathrm{II}), \mathrm{Co}(\mathrm{II}), \mathrm{Ni}(\mathrm{II})$, $\mathrm{Cd}(\mathrm{II}), \mathrm{Cu}(\mathrm{II}), \mathrm{Zn}(\mathrm{II}), \mathrm{Cr}(\mathrm{III})$ and Fe(III), with a Schiff base; (Z)-4-(1-((2-carboxycyclohexa-2,4-diene-1yl)imino)-ethyl)[bis( $\eta^{5}$-cyclopenta-1,3-diene-1-yl)]iron and 1,10-phenanthroline by using several tools. The antimicrobial activities of the Schiff base, 1,10-Phenanthroline and their mixed ligand complexes were tested against some pathogenic bacteria $S$. pneumoniae, B. subtilis, $P$. aeruginosa and E. coli] and fungi [A. fumigatu, S. racemosum, G. candidum and C. albicans] strains. The obtained data showed more active for the mixed ligand than the free ligands.

The preparation and characterization of the mixed ligand complexes derived from the reaction of 2,6pyridinedicarboxaldehydebis(p-hydroxyphenylimine), 2,6-pyridine carboxaldehyde bis(ohydroxyphenylimine) and 2-aminopyridine were reported by Mohamed et $\mathrm{al}^{11}$. The antimicrobial activity of the ligands and their mixed ligand complexes have been tested and compared with some known antibiotics.

Four $\mathrm{Co}(\mathrm{II}), \mathrm{Ni}(\mathrm{II}), \mathrm{Cr}(\mathrm{III})$ and $\mathrm{Zn}(\mathrm{II})$ mixed ligand complexes with the Schiff base derived from 4dimethylaminobenzaldehyde and 2-aminophenol as primary ligand and 2-aminobenzoic acid as secondary ligand were studied ${ }^{12}$. The antibacterial activities of the above were studied and found that the mixed ligand chelates have most biological activity in comparison to the free ligands and salts.The $\mathrm{Co}(\mathrm{II})$ complexes of a Schiff base; 2-amino-4-nitrophenol-N-salicylidene with some amino acids have been synthesized and investigated by Patil et $\mathrm{al}^{13}$. The Schiff base and its mixed ligand complexes were tested against some strains of microbes to study their biological effects.

The mixed ligand complexes of $\mathrm{Co}(\mathrm{II}), \mathrm{Ni}(\mathrm{II}), \mathrm{Cu}(\mathrm{II}), \mathrm{Cd}(\mathrm{II}), \mathrm{Zn}(\mathrm{II})$ and $\mathrm{Hg}(\mathrm{II})$ with a Schiff base (3) formed from the reaction of benzofuran-2-carbohydrazide and 3, 4, 5-trimethoxybenzaldehyde as primary ligand and malonyldihydrazide as secondary ligand were synthesized and characterized by Halli et al ${ }^{14}$. The antibacterial and antifungal activities of the Schiff base, malonyldihydrazide and their complexes have been examined against some pathogenic bacteria [S. aureus and E. coli] and fungi [A. flavus and A. niger] species. It was evident from the obtained results that the antibacterial and antifungal activities of all the compounds were increased on complexation. The increased activity may be interpreted on the basis of chelation theory ${ }^{15}$.

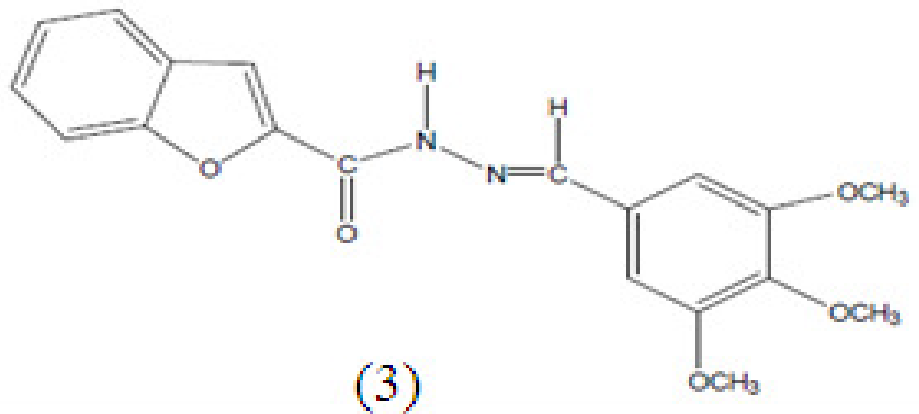

The Schiff base; N1-benzylidenebenezene-1,2-diamine (4)was prepared from the condensation of benzaldehyde and o-aminoaniline. Mixed ligand complexes (Fig.-2) of the Schiff base were prepared from chloride salts of $\mathrm{Zn}(\mathrm{II}), \mathrm{Cd}(\mathrm{II})$ and $\mathrm{Hg}(\mathrm{II})$ in ethanol and 8-hydroxyquinoline(8HQ) in the presence of $\mathrm{NaOH}$. The prepared complexes were investigated on the basis of various spectroscopic techniques. The antibacterial activity of Schiff base, $8 \mathrm{HQ}$ and mixed ligand complexes have been screened against some pathogenic bacteria (gram positive) and (gram negative) species. A comparative study of Schiff base, 8-hydroxyquinoline and their mixed ligand complexes exhibited that free 8-hydroxyquinoline showed a lower antibacterial activity than their mixed ligand complexes, while, Schiff base compound revealed higher activity except for Providencia. All mixed ligand complexes showed a negative effect against the growth of Providencia except mercuric complex, which indicated the existence of moderate effect. The same complex exhibited positive effect against four organisms which shows moderately to high activity. The increased inhibition activity of the mixed ligand complexes can be interpretated on the basis of chelation theory. In mixed ligand complexes, on complexation process, the polarity of the metal 
RASĀYAN J. Chem.

Vol. 11 | No. 1 |166-174 | January - March | 2018

ion might be reduced to a greater extent due to the overlap of the partial sharing of the positive charge and the metal ion ligand orbital with donor groups. ${ }^{16,17}$

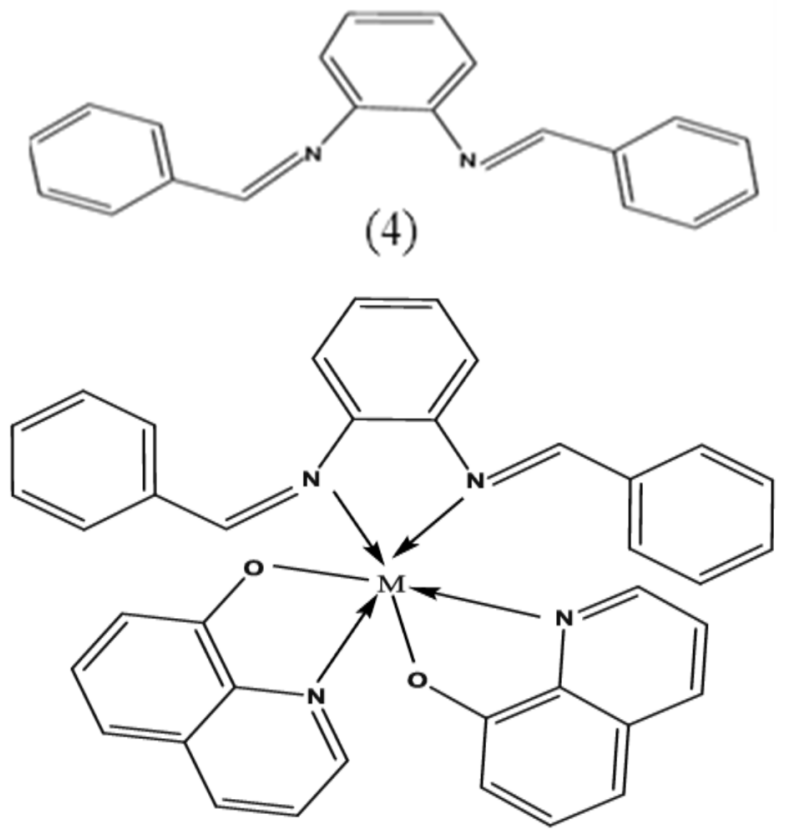

Fig-2:Structure of the mixed ligand complexes

The mixed ligand chelates of some divalent transition metal ions derived from 4-chloroaniline with salicylaldehyde or benzaldehyde, also 2-aminophenol or 4-nitroaniline with 2-hydroxyacetophenone, as well as with 4, 4-dimethylaminobenzaldehyde have been synthesized and investigated. The synthesized mixed ligand chelates were assayed for antibacterial activity against some pathogenic bacteria. The mixed ligand chelates exhibited higher antibacterial activity than the free ligands because of chelation ${ }^{18,19}$.

The ternary cerium (III) complexes with 2, 3-dimethyl-1-phenyl-4-salicylidene-3-pyrazolin-5-one and some amino acids (L-tryptophan, L-tyrosine, L-cysteine, L-leucine and L-serine) have been synthesized by Lokhande et $a l^{20}$. These complexes were characterized on the basis of several physicochemical techniques. Here the Schiff base; 2, 3-dimethyl-1-phenyl-4-salicylidene-3-pyrazolin-5-one acts as a primary ligand and amino acids acts as secondary ligands. The antimicrobial activities against $S$. aureus, C. diphtheriae, P. aeruginosa and E. coli showed that the complexes have better activity than that of each ligand.The increasing in the activity is due to the structures of the ligands containing an additional azomethine $(-\mathrm{C}=\mathrm{N})$ linkage and appear to be more liable to deactivation by metal ions upon chelation.

Some mixed ligand complexes of $\mathrm{Mn}(\mathrm{II}), \mathrm{Co}(\mathrm{II}), \mathrm{Cu}(\mathrm{II}), \mathrm{Ni}(\mathrm{II})$ and $\mathrm{Zn}$ (II), (Fig.-3) with o-vanillidene-2aminobenzothiazole and 1,10-phenanthrolinewere synthesized and characterized by Neelakantan et $\mathrm{al}^{21}$. Also some Schiff base metal complexes of the above chelates with $o$-vanillidene-2-amino-N-(2-pyridyl)benzene sulfonamide were synthesized. The free compounds and their mixed ligand complexes were examined for their biological activities against some bacteria, fungi and yeast strains. The metal complexes showed more potent activities compared with the free compounds.

Prashanthi et $a l^{22}$ prepared and investigated $\mathrm{Ni}$ (II) mixed ligand complexes (Fig.-4) of 1,10phenanthroline and many Schiff bases. The antimicrobial activity of these mixed ligand complexes was tested against various microorganisms.It was found that the antimicrobial activity of binary complexes is less as compared to their corresponding tertiary complexes. This is due to the complexes possess a greater planar area and systems which make stacking more strongly. The changes in the antimicrobial activity of different complexes against pathogenic bacteria and fungi depend either on the difference in ribosomes of microbial cells or impermeability of the cells of the microbes. 
The $\mathrm{Cu}(\mathrm{II})$ and $\mathrm{Ni}(\mathrm{II})$ complexes (Fig.-5) with two Schiff bases; 2-((2,4-dimethylphenylimino)methyl)-6methoxy-4-nitrophenol and 2-((3,4-difluorophenylimino)methyl)-6-methoxy-4-nitrophenol were synthesized and characterized by Joshi et $\mathrm{al}^{23}$. The Schiff bases and their mixed complexes were screened for antimicrobial activity against pathogenic bacteria and fungi strains [S. aureus, S. pyogenes, E. coli, $P$. aeruginosa C. albicans, A. niger, A. clavatus] using broth dilution method.

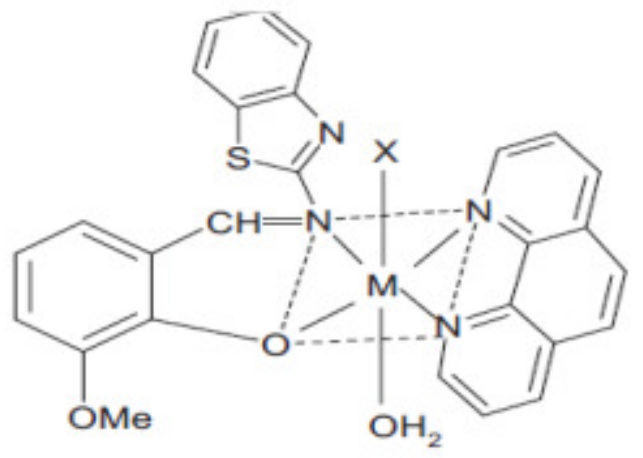

Fig-3: Structure of the mixed ligand complexes

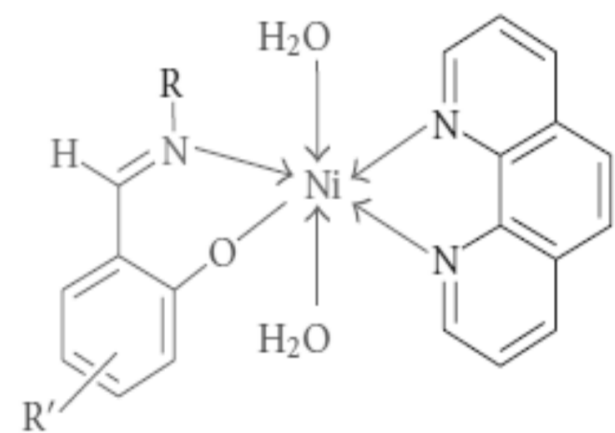

Fig-4: Structure of Ni(II) complex

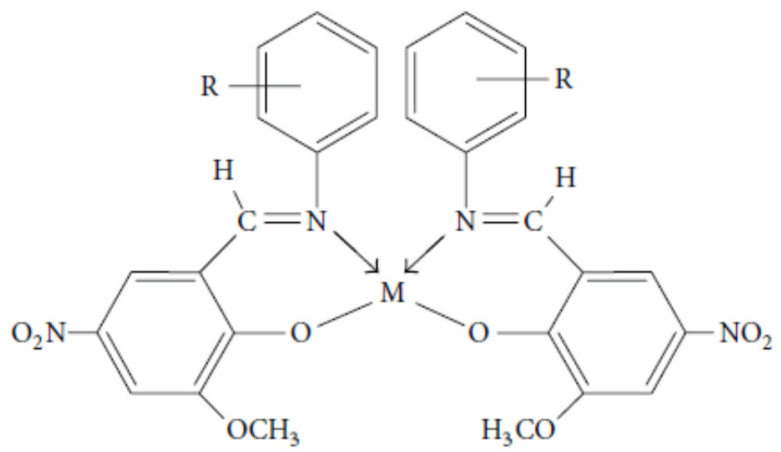

Fig-5: Structure of metal complex

A Mn(II) mixed ligand complex ${ }^{24}$ of two different Schiff bases, (Z)-2-((P-Tolylimino) methyl) phenol and 2-((E)-4-(E)-phenal-diazenyl) phenol were synthesized and investigated by using several physiochemical techniques. The in vitro antibacterial activities of the Schiff bases and their $\mathrm{Mn}$ (II) complex were screened using a number of pathogenic bacteria species such as E. coli, S. typhi, P. aeruginosa, S. pyogenes, and B. subtilis. 
Five mixed ligand chelates of di and trivalent transition metal ions with two ligands; (E)-2-(4(dimethylamino)benzylidene)aminophenol as the main ligand (5) and 2-aminobenzoic acid as coligand have been prepared and studied ${ }^{25}$. From the experimental data, an octahedral structure was suggested for all the chelates (Fig.-6). The antifungal activity the Schiff base, 2-aminobenzoic acid and their mixed ligand chelates against some pathogenic fungi was tested by using agar well diffusion method. The obtained data (Fig.-7,8,9,10) showed that some of the chelates have most activity against $A$. niger, A. flavus, Alternaria alternata, Rhizopus stolonifer.

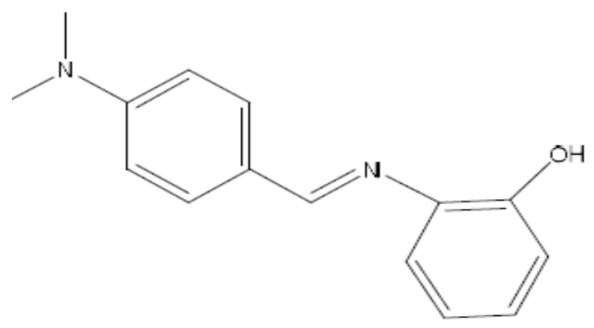

(5)

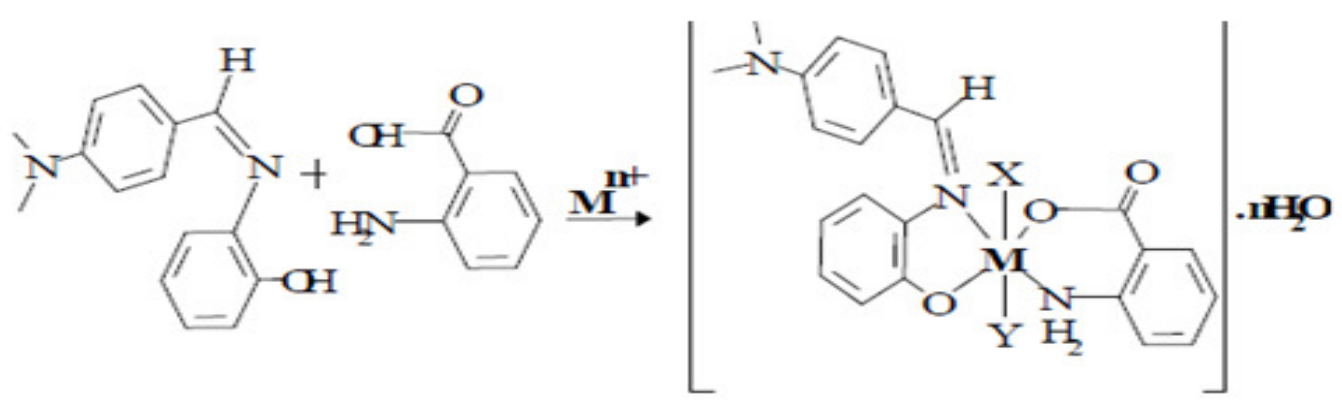

Fig.-6: Structure of the mixed ligand chelates

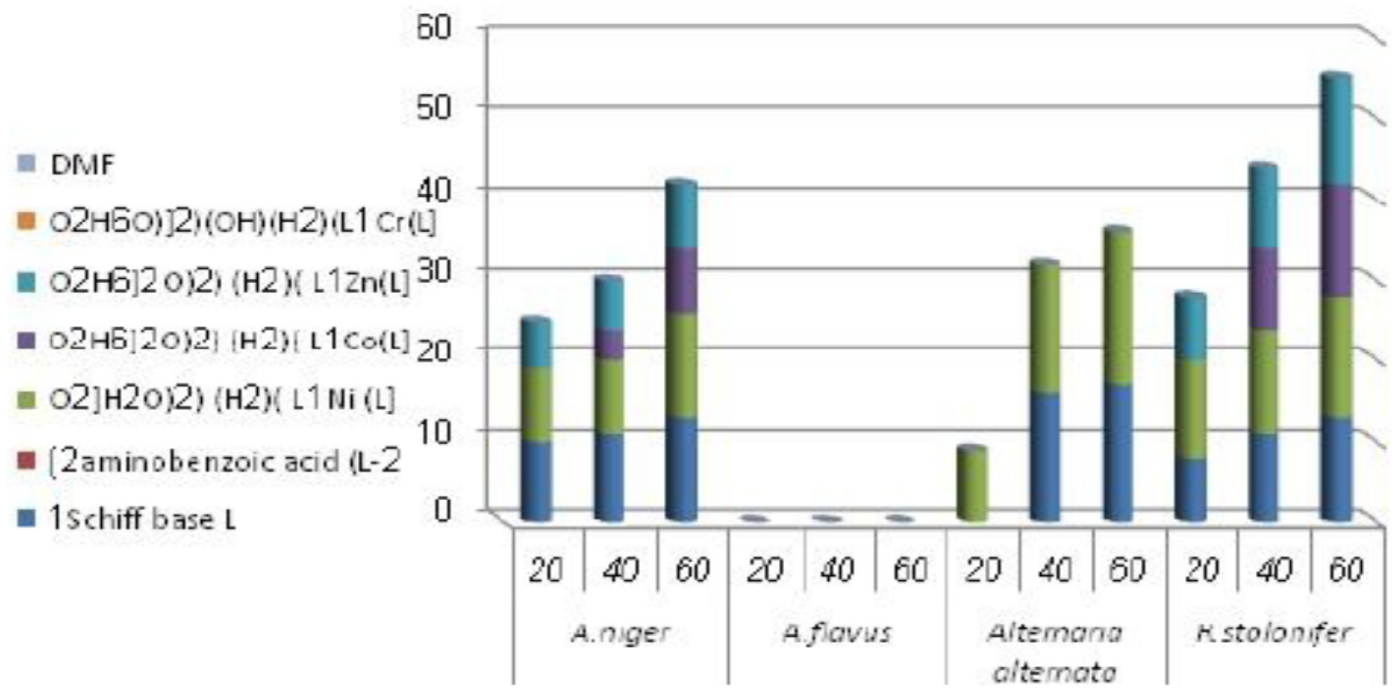

Fig.-7: Chart of comparison against four fungal species

Synthesis and investigation of five mixed ligand chelates of $\mathrm{Co}(\mathrm{II}), \mathrm{Ni}(\mathrm{II}), \mathrm{Cu}(\mathrm{II}), \mathrm{Zn}$ (II) and $\mathrm{Cr}$ (III) with mixed ligands including a Schiff base [(E)-2-(4-(dimethylamino)benzylideneamino)phenol] derived from 4-dimethylaminobenzaldehyde and 2-aminophenol as main ligand and an amino acid(L-histidine) as coligand were reported ${ }^{26}$. The antibacterial activities of the Schiff base, histidine, metal salts and mixed 
ligand chelates were examined. It was found that the mixed ligand chelates have the most activity in comparison to the free ligands and salts.

The divalent transition metal mixed ligand complexes with Schiff bases; N-(2-hydroxy-1naphthylidene)-4-chloroaniline and $\mathrm{N}$-(2-hydroxybenzylidene)-2,3-dimethylaniline were prepared and their geometrical structures were studied by using several physiochemical tools ${ }^{27}$. The Schiff bases and their mixed ligand complexes were examined for their antimicrobial activity by using Disc Diffusion method, and it was found that the mixed ligand complexes have higher antimicrobial activity than the free ligands.

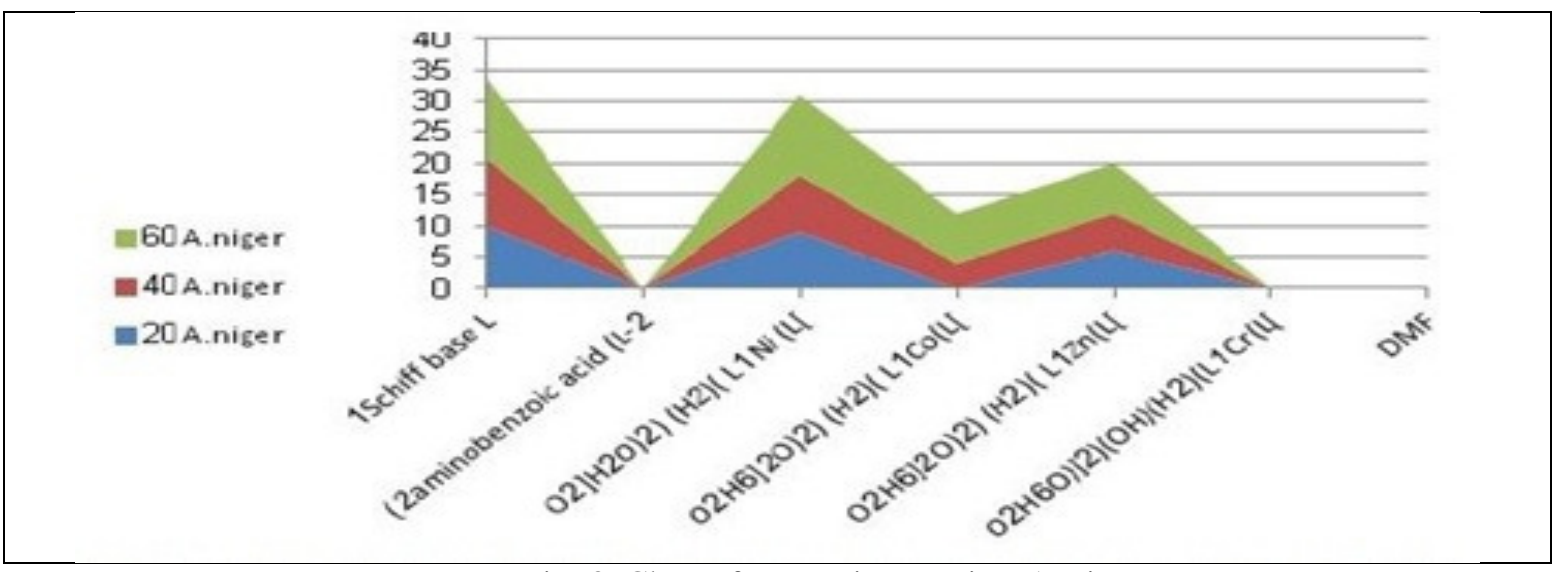

Fig.-8: Chart of comparison against A. niger

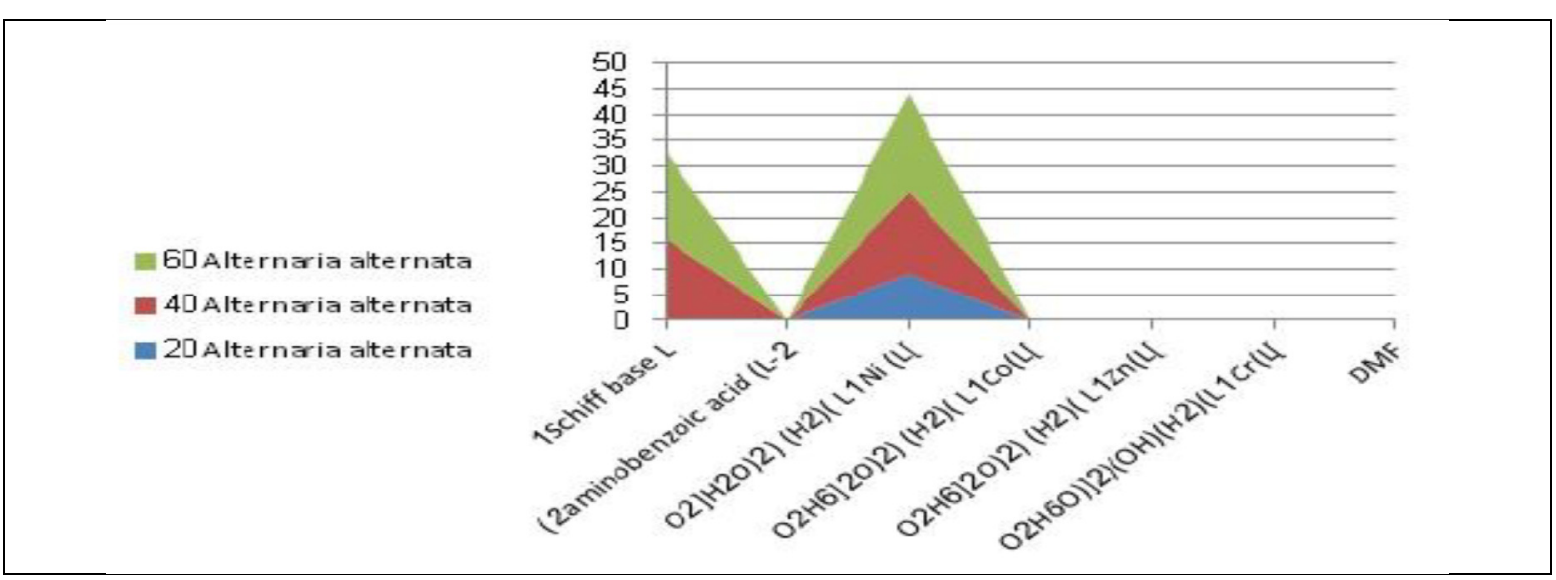

Fig.-9: Chart of comparison against A. alternata

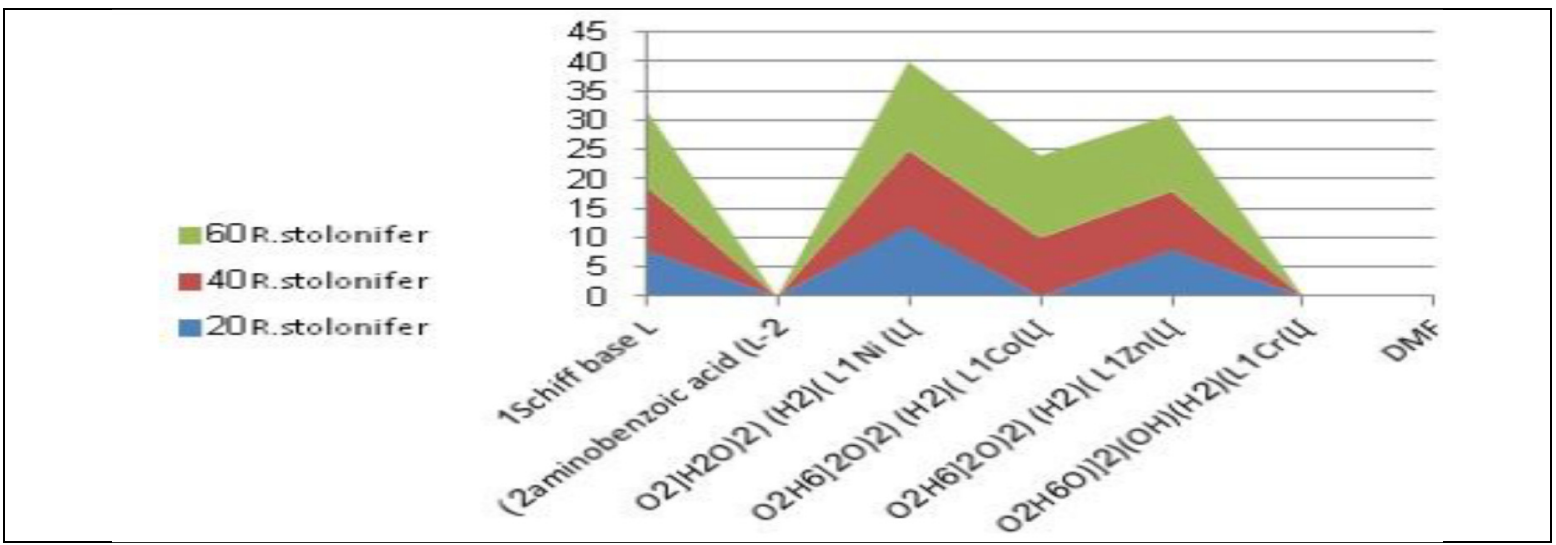

Fig.-10: Chart of comparison against R. stolonifer 
RASĀYAN J. Chem. Vol. 11 | No. 1 |166-174 | January - March | 2018

Four novel mononuclear $\mathrm{Cu}(\mathrm{II}) \quad \mathrm{Schiff}$ base complexes with 1-(((2-)((2hydroxypropyl)amino)ethyl)imino)methyl)naphthalene-2-ol), benzoic acid and salicylic acid were synthesized and characterized by Lian et $\mathrm{al}^{28}$. The X-ray diffraction study of these newly synthesized compounds was also carried out.The antiproliferative activity of these complexes against HeLa (human cervical carcinoma) and HepG-2 (human liver hepatocellular carcinoma) cells was evaluated. This study revealed that all the complexes had improved cytotoxicity against cancer cells.

New mixed ligand transition metal complexes were synthesized from a Schiff base obtained by the condensation reaction of oxamide and furfural as primary ligand and 2,2'-bipyridine as secondary ligand ${ }^{29}$.The ligands and their metal complexes were studied using various spectroscopic methods. The biological and anticancer activities of the new compounds were tested against breast cancer (MCF-7) and colon cancer (HCT-116) cell lines. The results showed high activity for the synthesized compounds.

A new Schiff base ligand derived from quinoline-2-carboxaldehyde with 2-aminophenol and its mixed ligand complexes with 2,2'-bipyridine have been synthesized by El-Halim et al $^{30}$. The X-ray diffraction study of these newly synthesized compounds was carried out. The Schiff base ligand and its mixed ligand complexes were also screened against some Gram-positive bacteria (Streptococcus pneumoniae, Bacillus subtilis), Gram-negative bacteria (Pseudomonas aeruginosa, Escherichia coli) and fungal species (Aspergillus fumigatus, Candida albicans). The results showed that all the mixed ligand complexes have antimicrobial activity higher than that of free ligand. Moreover, the anticancer activity of these compounds was tested against breast cancer cell line (MCF-7) and colon cancer cell line (HCT116).

\section{CONCLUSION}

This review presents a summary of the biological activities of Schiff bases and their mixed ligand-metal complexes. The majority of the studies described in this review were published very recently. The Schiff base compounds are also known to play a profound role in enzymatic reactions and in catalysis. Considering the facile synthetic methods of preparation and diverse application, more importantly as antifungal and antibacterial agents, the mixed ligand complexes containing Schiff base moieties hold a lot of significance for chemists and more over this review, though a brief one, will certainly enable them to design new molecules of mixed ligand complexes with different metal ions with greater potential applications in this field.

1. H. Schiff, Annalen., 131, 118(1864).

\section{REFERENCES}

2. M. M. El-ajaily and A. A. Maihub, Al-Mukhtar Journal-Beida University, Libya, 10, 70 (2003).

3. W. Rehman, F. Saman and I. Ahmed, Russ. J. Coord. Chem., 34(9), 678 (2008).

4. M. Wang and L. F. Wang, Trans. Met. Chem., 26, 307 (2000).

5. L. Ronconi and P. J. Sadler, Coord. Chem. Rev., 251, 1633 (2007).

6. M. M. El-ajaily,F. S. Alassbaly,A. M. Etorki and A. A. Maihub, Inter.Res. J. of Pure \&Applied Chemistry, 5(3), 229 (2015).

7. U. Doraswamy andP. K. Bhattacharya, J. Inorganic and Nuclear Chemistry, 37(7-8), 1665 (1975).

8. N. S. Al-barki,A. A. Maihub, M. M. El-ajailyandT. H. Al-Noor, Academic J. of Chemistry", 1( 3), 66 (2016).

9. N. A. Mazlan, T. B. S. A. Ravoof, E. R. T. Tiekink, M. I. M. Tahir and A. Veerakumarasivam, K. A. Crouse, Trans. Met. Chem., 39(6), 633 (2014).

10. W. H. Mahmoud, N. F. Mahmoud and G. G. Mohamed, J. Organometallic Chem., 848(15), 288 (2017).

11. G. G. Mohamed and Z. H. Abd El-Wahab, Spectrochim. Acta A: Mol. Biomol. Spectrosc.,61(6), 1059 (2005).

12. F. S. Alassbaly, M. M. El-ajaily,S. F. Ben-Gweirif and A. A. Maihub, J. Chem. Soc. Pak., 36(6), 1034 (2014).

13. A. R. Patil, K. J. Donde, S. Raut, S. Vishwanath, R. Patil and R. S. Lokhande, J. Chem. Pharma. Res., 4(2), 1413 (2012). 
14. M. B. Halli, B. Vijayalaxmi, R. Patil, B. Sumathi and K. Mallikarjun, Der. Pharma Chemica, 4(6), 2360 (2012).

15. T. H. Al-Noor and L. K. Abdul Karim, TOFIQ Journal of Medical Sciences, 3(2), 64 (2016).

16. M. H. Shatha and O. Al Naimi, Saudi J. Pathol. Microbiol.,1(2), 36 (2016).

17. M. Usharani, E. Akila andR. Rajavel, J. Chem. and Pharmaceutical Res., 4(1), 726 (2012).

18. A. A. Maihub, M. M. El-ajaily and S. S. Hudere, Asian J. Chem.,19(1), 1 (2007).

19. N. K. Fayad, T. H. Al-Noor and F. H. Ghanim, J. Advances in Physics Theories and Applications, 9, $1(2013)$.

20. B. D. Aghav, S. K. PatilandR. S. Lokhande, Advances in Applied Science Research, 6(12), 37 (2015).

21. M. A. Neelakantan, M. Esakkiammal, S. S. Mariappan, J. Dharmaraja and T. Jeyakumar, Indian J. Pharmaceutical Sciences, 72(2), 216 (2010).

22. Y. Prashanthi, K. Kiranmai, Ira,K. K. Sathish, V. K. Chityala and Shivaraj, Bioinorganic Chemistry and its Applications, 2012, Article ID: 948534 (2012).

23. K. R. Joshi, A. J. Rojivadiya and J. H. Pandya, Int. J. Inorganic Chem., 2014, Article ID: 817412(2014).

24. R. Jahan, Int. J. Engineering Studies and Technical Approach, 2(4), 5(2016).

25. M. M. Miloud, F. S. Alassbaly, M. M. El-ajaily and T. H. Al-Noor, J. Biol. Chem. Chron., 2(2), 42 (2016).

26. F. S. Alassbaly, A. A. Maihub, S. F. Ben-Gweirif, M. M. El-ajaily and T. H. Al- Noor, Saudi J. Pathol. Microbiol., 1(2), 29 (2016).

27. A. K. Mapari and K. V. Mangaonkar, Int. J.ChemTech. Res., 3(1), 477 (2011).

28. W. J. Lian,X. T. Wang,C. Z. Xie,H. Tian,X. Q. Song,H. T. Pan,X. Qiaoand J. Y. Xu, Dalton Trans., 45, 9073 (2016).

29. M. M. Omar, H. F. A. El-Halim and E. A. M. Khalil, Appl. Organomet. Chem., 31, e3724 (2017).

30. H. F. A. El-Halim, M. M. Omar and M. N. Anwar, J. Therm. Anal. Calorim., 130(2), 1069 (2017).

[RJC-1988/2018] 